\title{
Eccrine porocarcinoma on the cheek
}

\author{
Bommie Florence Seo, \\ Hyuk Joon Choi, \\ Sung-No Jung \\ Department of Plastic and \\ Reconstructive Surgery, Uijeongbu St. \\ Mary's Hospital, College of Medicine, \\ The Catholic University of Korea, \\ Uijeongbu, Korea
}

\begin{abstract}
Eccrine porocarcinoma is a rare malignant tumor arising from the intraepidermal ductal portion of the eccrine sweat gland. It develops either spontaneously or from a long standing benign eccrine poroma. This entity usually affects older people and is commonly located on the lower extremities, the trunk, and the head. We report a case of eccrine porocarcinoma on the left cheek in an 85-year-old male. In our case, the tumor was treated with wide excision and postoperative adjuvant radiation therapy. The patient recovered well without local recurrence and distant metastasis during the 14-month follow-up period. Wide excision and postoperative adjuvant radiation therapy can be considered as a safe and effective treatment option in treating patients with eccrine porocarcinoma.
\end{abstract}

Keywords: Adjuvant radiotherapy / Eccrine porocarcinoma / Sweat gland neoplasm

\section{INTRODUCTION}

Eccrine porocarcinoma is a malignant tumor originating from the intraepidermal ductal portion of the eccrine sweat gland, which accounts for approximately $0.005 \%$ of epidermal skin tumors [1]. It was first reported by Pinkus and Mehregan [2] in 1963. It occurs mainly in long-lasting benign eccrine poroma and rarely occurs as a primary lesion. Clinically, it appears in the form of an ulcerative nodule or tumor. Histologically, it can grow horizontally in the epidermis to the periphery, invade to the dermal layer or subcutaneous fat layer and cause metastasis to the internal organs [3]. We report a case of a malignant eccrine gland tumor on the face with a review of the literature.

\section{CASE REPORT}

An 85-year-old man presented with a 1-cm diameter mass accompanied by erosive eczema on the left cheek. This mass oc-

\footnotetext{
Correspondence: Sung-No Jung

Department of Plastic and Reconstructive Surgery, Uijeongbu St. Mary's Hospital, College of Medicine, The Catholic University of Korea, 271 Cheonbo-ro, Uijeongbu 11765, Korea

E-mail: jsn7190@hanmail.net

Received September 20, 2018 / Revised October 24, 2018 / Accepted October 30, 2018
}

curred 5 years before the visit to the hospital, gradually increasing in size. On physical examination, no other lesions were observed in the head and neck. An eczematous lesion with an eschar on the left wrist was found to be Bowen disease on a pathologic examination. The patient had a history of adenoma of the ampulla of Vater and cataract. Blood tests, urinalysis, and liver and kidney function tests were normal. Chest $\mathrm{X}$-rays were negative except for old tuberculosis.

Under local anesthesia, wide excision with a $0.5-\mathrm{cm}$ safety margin was performed. Frozen biopsies confirmed that there was no invasion on the resected surface. Pathology results revealed a poorly defined eccrine porocarcinoma. Histopathologically, partial acanthosis was observed in the epidermis and nests of various sizes composed of polygonal or basal cell carcinoma cells extending from the epidermis to the dermis were observed. Tumor cells had atypical nuclei with frequent mitoses, some changes in the amount of clear cells, and partly formed ductular structures (Fig. 1). At 3 months postoperatively, a nodule was palpable in the left cervical region and ultrasoundguided fine needle aspiration biopsy was performed. Metastasis to the left cervical lymph node was confirmed and radiotherapy (70 Gy/35 fractions) was performed on the left neck for 3 months under the consultation of the radiation oncology. Re- 

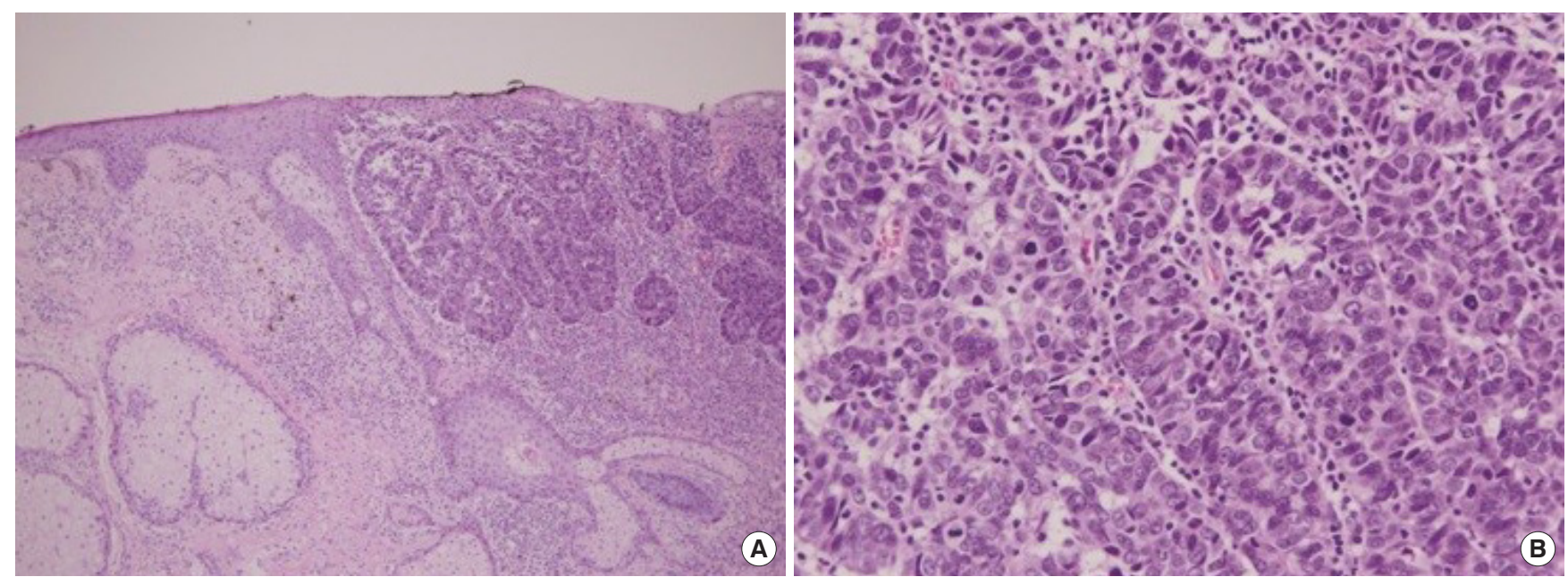

Fig. 1. Histologic findings. (A) The epidermis showed acanthosis and large islands of tumor cells (H\&E, $\times 100)$. (B) The tumor cells have nuclear atypia with frequent mitoses. They formed ductular structures $(\mathrm{H} \& \mathrm{E}, \times 400)$.
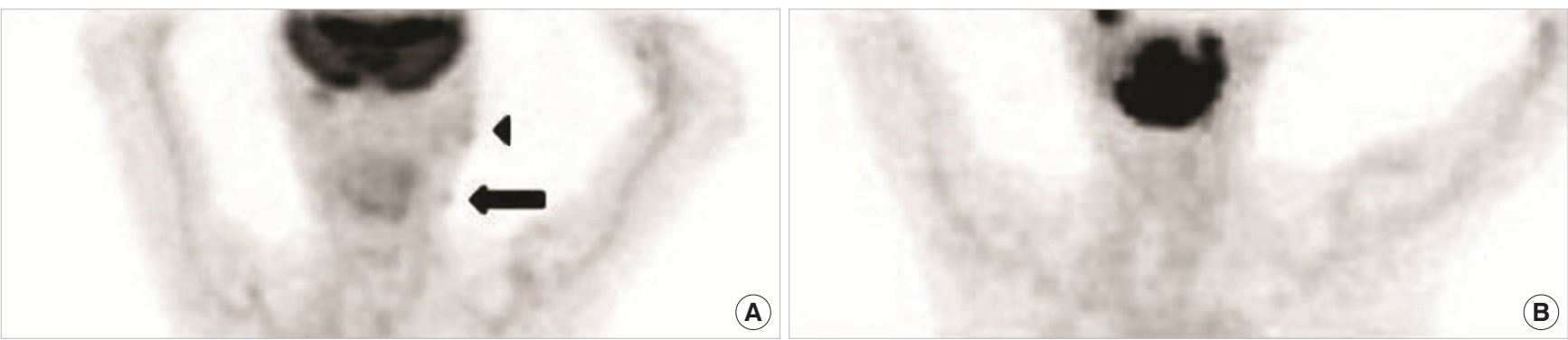

(A)

(B)

Fig. 2. Positron emission tomography-computed tomography findings. (A) At postoperative 3 months, diffuse increase of metabolism (arrowhead) on outer margin of left parotid gland and mild increase of metabolism on small nodule of left upper neck (arrow) were seen, indicating low grade malignancy in left parotid gland and regional lymph node of ipsilateral upper neck. (B) After radiation therapy for 3 months, decrease of hypermetabolic lesions were observed, as in metabolic remission state.
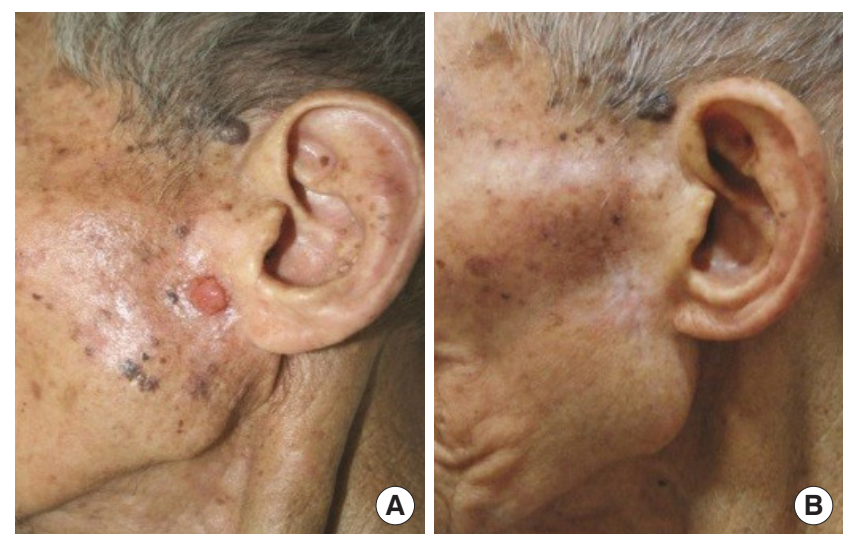

Fig. 3. (A) Preoperative photograph of an 85-year-old man with a polypoid mass on the left preauricular region, measuring $1 \mathrm{~cm}$ in diameter. (B) At postoperative 14 months, the patient showed no sign of local recurrence, without significant complications.

mission was confirmed by positron emission tomographycomputed tomography) (Fig. 2). There was no recurrence or metastasis during the follow-up period of 14 months (Fig. 3).

\section{DISCUSSION}

Eccrine porocarcinoma, a malignant tumor of the eccrine gland, originates from the intraepidermal duct of the gland and occurs most commonly in the order of lower limb (44\%), trunk (24\%), and head (18\%) in the elderly [4]. Most lesions develop long before time ago and the duration varies from 2 months to 50 years. Eccrine porocarcinomas may occur as a primary lesion, but most of the lesions originate from a long-standing benign eccrine poroma, and may be accompanied by sebaceous gland, extra-mammary Paget's disease, or Hodgkin's lymphoma [5]. It usually occurs in the form of red ulcerative plaques, nodules, or tumors. Sudden rapid growth, ulcerative changes, and multiple lesions suggest local recurrence or metastasis to surrounding organs such as the lymph nodes, lung, liver, bladder, peritoneum, and retroperitoneum [6].

Eccrine porocarcinoma originating from previous benign eccrine poroma is characterized by the presence of atypical cells with large and irregular shaped hyperchromatic nucleus adja- 
cent to cuboidal cell of eccrine poroma with basophilic round nuclei. In addition, there can be lumps of tumor cells different in shape from surrounding squamous cells with definite boundaries [7]. In primary tumors, the malignant cells are localized within the epidermis or invade into the dermis, severe acanthosis is observed in the epidermis due to the proliferation of tumor cells, and cystic lumen is also observed in several lumps of tumor cells. Recent studies have performed immunohistochemical staining using carcinoembryonic antigen (CEA), epithelial membrane antigen (EMA), and S-100 protein. CEA and EMA were positive in the intraepidermal ductal cell, and S-100 protein was negative [8]. Histologically, when the tumor cells are localized within the epidermis, it is necessary to differentiate from hidroacanthoma simplex, Bowen's disease, seborrheic keratosis among others. When extensive infiltration into the dermis of the tumor cells is seen, basal cell carcinoma, squamous cell carcinoma and the like should be distinguished.

Treatment should be performed with wide excision to completely remove the tumor, and prophylactic surrounding lymph node dissection is also needed [1]. Recent studies have shown that the prognosis is poor when (1) there are more than $14 \mathrm{mi}-$ toses at high magnification, (2) there is evidence of lymph node metastasis, and (3) the tumor invasion depth is greater than 7 $\mathrm{mm}$. In addition, it has been reported that wide excision is necessary when the margin of the tumor is invasive because local metastasis is well developed [4]. After wide excision, local recurrence occurs in $20 \%$, regional lymph node metastasis in $20 \%$ and distant metastasis in about $10 \%$ of patients. Clinically, multinodular or ulcerative lesions, or lesions with rapid growth rate have frequently recurred after wide excision. It is known that recurrence leads to poor prognosis and most patients die from metastasis without responding to chemotherapy or radiotherapy [4].

In the documented case here, wide excision was performed for the eccrine porocarcinoma on the left cheek. After surgery, radiation therapy was administered for the involvement of the left cervical lymph nodes. There was no recurrence or distant metastasis during the follow-up period of 14 months, and the patient's general condition was also satisfactory.

\section{NOTES}

\section{Conflict of interest}

No potential conflict of interest relevant to this article was reported.

\section{Ethical approval}

The study was performed in accordance with the principles of the Declaration of Helsinki. Written informed consent was obtained.

\section{Patient consent}

The patient provided written informed consent for the publication and the use of his images.

\section{ORCID}

Bommie Florence Seo https://orcid.org/0000-0002-6907-5962

Hyuk Joon Choi https://orcid.org/0000-0001-9681-628X

Sung-No Jung

\section{REFERENCES}

1. Barton RM. Malignant tumors of the skin. In: Mathes SJ, editor. Plastic surgery. 2nd ed. Philadelphia: Saunders Elsevier; 2006. p. 298.

2. Pinkus H, Mehregan AH. Epidermotropic eccrine carcinoma: a case combining features of eccrine poroma and Paget's dermatosis. Arch Dermatol 1963;88:597-606.

3. Brown CW Jr, Dy LC. Eccrine porocarcinoma. Dermatol Ther 2008;21:433-8.

4. Robson A, Greene J, Ansari N, Kim B, Seed PT, McKee PH, et al. Eccrine porocarcinoma (malignant eccrine poroma): a clinicopathologic study of 69 cases. Am J Surg Pathol 2001;25:71020.

5. Snow SN, Reizner GT. Eccrine porocarcinoma of the face. J Am Acad Dermatol 1992;27(2 Pt 2):306-11.

6. Puttick L, Ince P, Comaish JS. Three cases of eccrine porocarcinoma. Br J Dermatol 1986;115:111-6.

7. Huet P, Dandurand M, Pignodel C, Guillot B. Metastasizing eccrine porocarcinoma: report of a case and review of the literature. J Am Acad Dermatol 1996;35(5 Pt 2):860-4.

8. Claudy AL, Garcier F, Kanitakis J. Eccrine porocarcinoma: ultrastructural and immunological study. J Dermatol 1984;11: 282-6. 